\title{
Tema 4. Desarrollo cognitivo o del pensamiento en la infancia
}

\section{Presentación}

Para pensar el desarrollo cognitivo del niño es recomendable estudiar la obra de Jean Piaget desde una perspectiva realmente interdisciplinaria y desde un enfoque constructivista. Piaget hizo uso de los propios fundamentos de su elaborada epistemología genética o epistemología científica acerca de la construcción del conocimiento para definir las operaciones centrales del pensamiento lógico-matemático, del desarrollo moral y las etapas centrales del pensamiento humano.

\section{Propósito (objetivo)}

Motivar al docente y al padre de familia para que realicen una exploración y asimilación de los aportes esenciales del estudio piagetiano con el propósito de adquirir elementos conceptuales que enriquezcan su mirada sobre los distintos estilos de pensamiento que se presentan en el niño, considerando cuáles de estos fortalecen su autonomía y capacidad reflexiva. 


\section{Conceptualización general}

Existen dos niveles de análisis que es importante abordar en el pensamiento de Jean Piaget para lograr un mínimo acercamiento a su teoría: la operación del pensamiento y el desarrollo de las etapas de la inteligencia ${ }^{1}$.

\section{Pensamiento operacional}

Más allá de una concepción que comprende la sensación y la percepción como el origen de los conocimientos que cree en el empirismo como el fundamento del desarrollo científico, Piaget sostiene que si bien estas tienen un papel preponderante en las primeras etapas del desarrollo nunca operan solas. El progreso del conocimiento es deudor de las acciones que siguen a las sensaciones, y así la hipótesis piagetiana se formula en los siguientes términos: nuestros conocimientos no provienen únicamente de la sensación ni de la percepción, sino de la totalidad de la acción con respecto de la cual la percepción solo constituye la función de señalización, puesto que lo propio de la inteligencia no es contemplar, sino "transformar" y su mecanismo es esencialmente operatorio.

La transformación de los objetos, es decir, la estructuración y esquematización que sobre estos realiza el sujeto, enseña Piaget, se da de dos modos: de forma física, cuando se trata de modificar la posición del objeto o sus propiedades para investigar su configuración, y de modo lógico-matemático, cuando se nutre el objeto con relaciones novedosas por medio de sistemas de acción centradas en operaciones. De lo anterior se desprenden dos tipos de experiencia que corresponden a las dos formas de estructuración: la experiencia física y la experiencia lógico-matemática, procedimientos y operaciones.

En concordancia con la teoría piagetiana se plantea que algunas de las operaciones del pensamiento no se dan aisladamente sino que

1 La elaboración conceptual que presento sobre los textos de Piaget hace parte de la tesis Función y limite de la voluntad de saber (1997). 
se instalan a través de su naturaleza esquemática, se sitúan como una caja de herramientas, como cualidades benéficas para el progreso y la transformación de la inteligencia. Las operaciones lógico-matemáticas tienen la propiedad de poder ser interiorizadas y de ser reversibles, entre ellas se destacan: las clasificaciones, el discernimiento de la transitividad y de la conservación, la reversibilidad, y la lógica del número (la inclusión y la seriación).

En torno a la lógica de las estructuras del conocimiento, Piaget destaca el pilar fundamental de su enseñanza: la acción como interacción. Y frente a la indagación por la división entre lo lógico-operacional y lo físico critica la diferencia que hace el Círculo de Viena entre una verdad lógica que se soporta sobre la pura formalización y una verdad proposicional basada en los hechos. Sugiere que es indispensable y necesaria la función determinante de la experiencia como base de todo conocimiento, aunque sea formal, así, por ejemplo, una verdad como $2+2=4$ supone la presencia anterior de una experiencia; de igual manera, para construir la lógica elemental transitiva, por ejemplo, 4 - 2 = 2, el niño necesitará de la experiencia, de la acción. En síntesis, la estructura del lenguaje, y en especial del lenguaje formal, es dependiente de la experiencia como coordinación de la acción entre estructuras y procedimientos.

Para la comprensión de las clasificaciones, o también llamadas agrupaciones de clases, el niño comienza a esquematizarlas a partir de las colecciones de figuras, luego logra agrupar los objetos según semejanzas o diferencias, y finalmente se figura o imagina colecciones formales de ideas o de subconjuntos a nivel racional. El entendimiento de la idea de conservación estipula que el esquema de permanencia debe asumirse también cuando el objeto está ausente o por fuera del campo de percepción del sujeto. Así, se distinguen dos casos, el esquema de permanencia-conservación por invariantes sensomotoras, o sea las constantes perceptivas de la magnitud, la forma, el color, etc., y el esquema de permanencia por invariantes del pensamiento que implica la conservación de la noción de conjunto, magnitud espacial, cantidad física, etc. Entonces, la invariante de la conservación del objeto se construye primero en función de la percepción de los desplazamientos del objeto y, posteriormente, gracias a las invariantes representativas que 
quedan en la mente como correlativas a la construcción de las nociones de clase o de conjunto.

Otro de los mecanismos centrales es la configuración de la intelección de la reversibilidad. Piaget expone que esta es la expresión pura de la transformación de las acciones en operaciones. En el niño, las primeras acciones son de sentido único: son elementales, se someten a una interiorización de la acción bajo la forma de una representación imaginada de carácter irreversible, y posteriormente las acciones se coordinan en sistemas posibles de reversibilidad, donde cada operación tiene su contraparte inversa. Esto último es producto de la riqueza de los esquemas que se han incrementado en el transcurso del florecimiento de los procedimientos mentales.

\section{Etapas del desarrollo cognitivo}

Dentro del proceso de desarrollo del pensamiento, Piaget distingue varias etapas, que se presentan en un periodo de florecimiento más o menos definido. Tal intervalo no siempre coincide con la edad cronológica de los niños, pues cada uno está sometido a condiciones diferentes por su entorno y la influencia e intensidad de las variables culturales difiere en cada lugar. En realidad, más allá de una definición exacta del periodo, lo importante es la verificación de sus aportes en las manifestaciones propias de cada etapa de desarrollo. Dichas etapas se instauran a partir del nacimiento del niño y tienen su término en la madurez del adolescente, tienen características fundamentales y se ordenan de la siguiente manera:

- Periodo sensorial-motor: está delimitado más o menos entre los cero a dos años de edad, se reconoce por la presencia de egocentrismo, y tiene como mayor logro la organización de acciones sensoriales-motrices a nivel perceptivo, y la construcción de la noción de objeto permanente ${ }^{2}$. Esta etapa es preponderante

2 Es importante que en este punto se recuerden algunos de los conceptos del segundo tema, especialmente la descripción sobre el desarrollo del niño en su primer año de vida. 
para el desarrollo del pensamiento ya que "[...] el niño elabora a ese nivel el conjunto de las subestructuras cognoscitivas que servirán de punto de partida a sus construcciones perceptivas e intelectuales ulteriores [...]" (Piaget, 1975, p. 15), por ello puede observarse que en este estadio predomina la experiencia o el desenvolvimiento sensorial y motor, la abstracción empírica sobre la reflexiva.

- Etapa preoperacional o preconceptual: se da entre los dos y siete años más o menos, se destaca aquí la capacidad que adquiere el niño para representarse el mundo, comienza a desarrollar procesos de inferencia causal y la noción de tiempo. Todo ello se soporta en la aparición e interiorización del lenguaje; el niño adquiere la capacidad de reconstruir sus acciones gracias a la verbalización, lo cual tiene tres consecuencias esenciales para el progreso del pensamiento: el intercambio con los individuos como comienzo de la socialización, la aparición de la palabra interiorizada como puro pensamiento, y la interiorización de la acción, que pasa de ser empírica o motriz al mundo de las imágenes mentales.

- Etapa de las operaciones concretas: se presenta entre los siete y once años, y en ella se logra el equilibrio de los logros de la etapa anterior, se presentan las organizaciones conceptuales y el desenvolvimiento de las estructuras de grupos y de clases, principalmente se interiorizan la reversibilidad y las combinaciones. A nivel social se adquiere la capacidad de cooperación, ya que el niño diferencia su opinión de la de los demás, lo cual es correlativo con la superación del lenguaje egocéntrico, y con el cambio de una posición heterónoma ante la reglas a una actitud autónoma. A nivel del pensamiento se presenta la superación del animismo, que da paso a las primeras explicaciones racionales.

- Etapa de las operaciones formales: se da en el intervalo de los once a los dieciséis años. En ella el joven da inicio al mundo de las posibilidades mentales, ya no solamente representa la 
realidad sino que intenta crear nuevos mundos de pensamiento. Al respecto relata Piaget: "Si lo comparamos con un niño, el adolescente es un individuo que construye sistemas y 'teorías'” (Piaget, 1985, p. 94). En esta etapa el joven presenta un profundo interés por problemas que carecen de actualidad, se involucra en la construcción de quimeras, es un soñador que ha llegado al estado de formalización y de abstracción del pensamiento. Ya ha logrado el paso o transposición de las operaciones lógicas sobre lo concreto a su aplicación efectiva en el plano de las ideas. En síntesis, logra desarrollar el modo de pensamiento hipotético-deductivo, base de la inteligencia científica. Esto deja sembrado el terreno para la formulación del siguiente estadio: el pensamiento científico, nivel en el que la abstracción se desprende de cualquier abstracción empírica, momento que libera el pensamiento de la realidad para darles paso a las operaciones sobre las operaciones, a la pura abstracción reflexiva.

\section{Acercamiento personal (reflexión)}

Después de abordar la conceptualización:

- ¿Cómo cree que se dan las relaciones entre las etapas de pensamiento y la adquisición de habilidades sociales y competencias ciudadanas?

- Plantee dos ejemplos que den cuenta del pensamiento egocéntrico del niño y dos ejemplos que muestren que ha logrado un pensamiento en el que tiene en cuenta la perspectiva del otro.

- ¿Cómo explicaría el paso de un pensamiento de carácter heterónomo a uno autónomo en el niño?

- Se dice que los niños de la calle desarrollan cierta "astucia", ¿qué tipo de pensamiento estaría desarrollando con ello? 


\section{Actividades sugeridas}

\section{Búsquedas en Internet y bibliotecas}

Búsquedas de casos en prensa

Preguntas para debates grupales
- Profundice en los conceptos destacados en cursiva en la sección de conceptualización general.

- Lea el libro de Henry Wallon Del acto al pensamiento (https://is.gd/yDgGW2) y haga un cuadro conceptual en el que muestre las similitudes y diferencias entre las etapas que se plantean allí con las presentadas por Piaget.

- En algunas situaciones los adultos conservan rasgos o conjuntos de esquemas del pensamiento de la niñez. Ilustre casos en los cuales un adulto presenta evasión de la responsabilidad mediante argumentos egocéntricos y heterónomos.

- En algunas ocasiones ciertos niños y niñas presentan un desarrollo cognitivo más avanzado que el promedio, incluso pueden razonar mejor que muchos adultos. ¿Aun así, por qué no se le puede tratar como un adulto? ¿Qué aspectos de su vida hay que proteger?

- ¿Creen ustedes que el desarrollo del pensamiento es garantía para construir un buen juicio moral, respeto por los otros y para apropiarse de la idea y práctica del bien común? ¿O es un aspecto necesario pero insuficiente para lograr una correcta moral? 


\section{Bibliografía básica}

McCabe, A. (2006). Developmental Psychology. En McGraw-Hill Concise Encyclopedia of Science and Technology. Nueva York: McGraw-Hill.

McLeod, S. (6 de junio de 2018). Jean Piaget's Theory of Cognitive Development. Simply Psychology, recuperado de https://is.gd/uiTclT

Piaget, J. (1954). La construcción de la realidad en el niño. Nueva York: Norton.

Piaget, J. y Inhelder, B. (1973). Memory and Intelligence. Londres: Routledge y Kegan Paul.

Piaget, J. e Inhelder, B. (1975). Psicología del niño. Madrid: Ediciones Morata.

Singer-Freeman, K. Concrete Operational Period. En N. Salkind, Encyclopedia of Human Development, 1 (pp. 291-292). Thousand Oaks: Sage.

Torres, J. y Ash, M. (2007). Cognitive Development. En C. Reynolds, K. Vannest y E. Fletcher-Janzen (eds.), Encyclopedia of Special Education: A Reference for the Education of Children, Adolescents, and Adults with Disabilities and Other Exceptional Individuals. Hoboken: John Wiley \& Sons.

\section{Bibliografía complementaria}

Acevedo, O. (1997). Función y límite de la voluntad de saber (tesis inédita). Universidad de Antioquia, Medellín, Colombia.

Furth, H. (1977). The Operative and Figurative Aspects of Knowledge in Piaget's Theory. Londres: Routledge y Kegan Paul.

Piaget, J. (1985). Seis estudios de psicología. Barcelona: Planeta.

Pulaski, M. (1978). El desarrollo de la mente infantil. Madrid: Paidós.

Traill, R. (2012). Una base molecular para "schème" de Piaget (como código de memoria): Algunas implicaciones sorprendentes. Ponencia presentada en la 42. ${ }^{a}$ Conferencia Anual de la Sociedad Jean Piaget, Toronto, Canadá.

Weinberg, R. (1989). Intelligence and IQ: Landmark Issues and Great Debates. American Psychologist, 44, 98-104. 



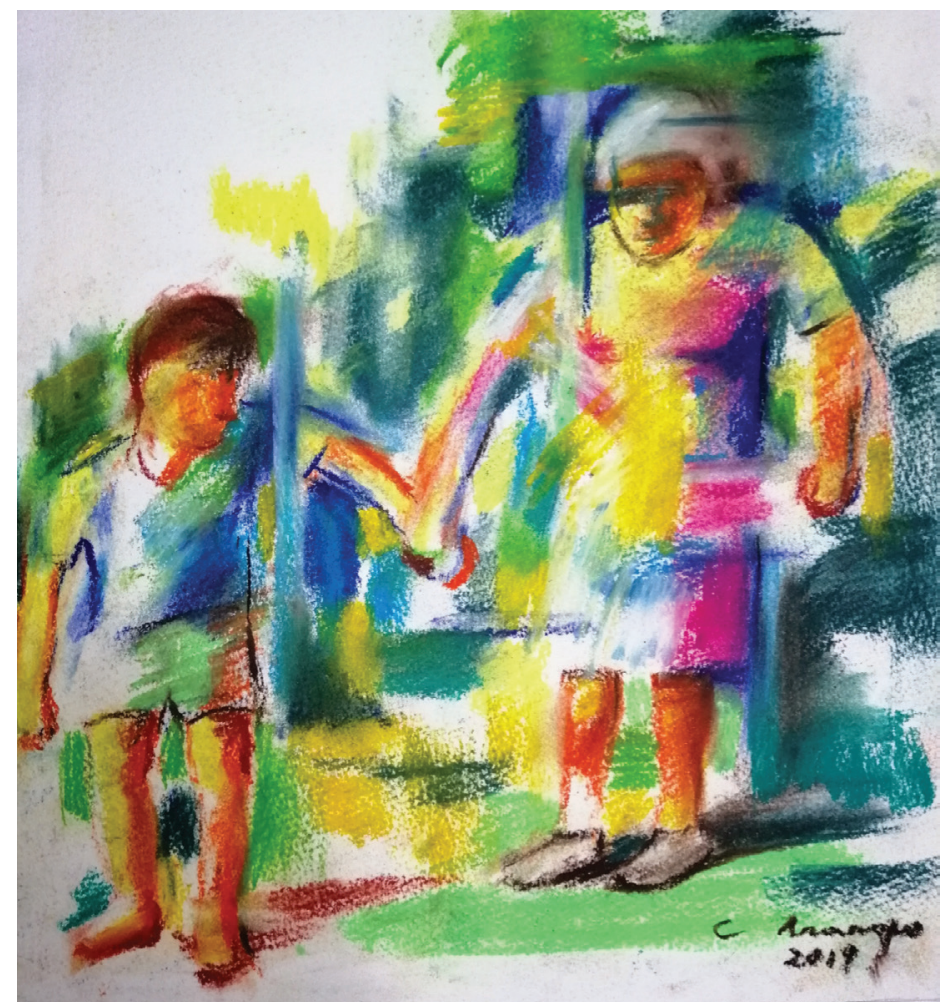

Para mi respetuoso es aquel que respeta a sus vecinos, aquel que sabe que sacar a su perro significa limpiar lo que el perro haga [...], aquel que sabe que hacer hasta el menor robo de electricidad está mal, aquel que sabe que no debe botar basura en la calle, sino esperar que pase el carro recolector, aquel que respeta las cosas de los demás vecinos.

Madre de familia Hogar Infantil Fundehi, barrio El Arroyo, Cazucá, Soacha, 2017 